\title{
The self-management of chronic illnesses: theories and technologies
}

\author{
Silvia Torsi, Peter Wright \\ Faculty of Art, Computing, Engineering and Sciences \\ Sheffield Hallam University \\ Sheffield, United Kingdom \\ \{s.torsi; p.c.wright\}@shu.ac.uk
}

\author{
Gail Mountain, Nasrin Nasr \\ School of Health and Related Reseach \\ University of Sheffield \\ Sheffield, United Kingdom \\ \{g.a.mountain; n.nasrin@sheffield.ac.uk\}
}

\author{
Sue Mawson \\ Centre for Health and Social Care Research \\ Sheffield Hallam University \\ Sheffield, United Kingdom \\ s.j.mawson@shu.ac.uk \\ Ben Rosser \\ Centre for Pain Research, School of Health \\ University of Bath \\ Bath, United Kingdom \\ b.rosser@bath.ac.uk
}

\begin{abstract}
A patient who is self-managing a chronic condition is actively involved in the prevention, understanding and regulation of his symptoms by means of his behavior and choices. We present the most acknowledged self-management theories and strategies, with an accent on those that can be relevant for supporting ICT solutions for Healthcare. Finally we review five projects about sensing technologies, mobile devices and ambient information displays for self-care and behavior change.
\end{abstract}

Keywords: Health and Social Care research, Self-Management, Self-Management theories, HCI, Healthcare HCI

\section{INTRODUCTION}

There is no consensus about the definition of selfmanagement. Barlow [1] defines self-management as the individual's ability to manage the symptoms, treatment, physical and psychological consequences and life style changes inherent in living with a chronic condition. Efficacious self-management encompasses ability to monitor one's condition and to affect the cognitive, behavioral and emotional responses necessary to maintain a satisfactory quality of life. Thus, a dynamic and continuous process of self-regulation is established with patient and health care provider working in successful partnership. There are several models of self-management, because different illnesses require different set of activities and attitudes. These models in part overlap each other and, in sum, depict a broad picture of the possible interventions for the range of chronic illnesses. According to Lorig and Holman [2] self-management is composed of four categories of strategy: (1) skills mastery or taking action: action planning, control with self efficacy and problem solving; (2) developing a model of the condition; (3) creating relationships with professionals and social networks with peers; and (4) acquiring skills in symptom interpretation.
Social persuasion is an important element for increasing selfefficacy; information and social pressure from peers have been found to be effective in the development of self-management actions and possible behavior that the patient can adopt to improve his situation. What follows is a description of the most relevant theories of self-management, which could be used as working tools for developing technologies supporting self-care and behavior change. These approaches are not always successful, depending this on a huge range of factors. To incorporate them through design into technologies is proposed here as an integrative strategy providing a wider array of instruments for the scaffolding of self-management and rehabilitation practices. Possible uses of these methods to be embodied in information and communication systems are intentionally left to the reader, this because the implications can be the resultant of design thinking based on the described self-management tools.

\section{SELF-MANAGEMENT THEORIES AND STRATEGIES}

\section{A. Self-efficacy}

Albert Bandura's Social cognitive theory [3] focuses on the interaction between the self, one's actions and cognitions, and the affective dimension of the environment. Human functioning is modeled as a result of personal, behavioral and environmental variables and affections. It is a strong paradigm for rehabilitation, especially when coupled with goal setting. Social cognitive theory relies on self-reflective introspection and self-beliefs as a valued device for human agency allowing us to make sense of our experiences, engage in self-evaluation, modify our thinking and, as a consequence, regulate our actions, acting on their environment and social systems. The core of these processes is in the human ability to symbolize, make sense of what happens, produce guides for action, 
provide life with continuity and communicate with others. This is possible through the manipulation of symbols, in a self-directed and thoughtful effort to change the course of one's actions [4]. The perceptions that one has of his efficacy to pursue a goal will affect his motivation, and provides anticipatory scenarios that he constructs and reiterates, and that provide trajectories for motivation and the pursuit of selfregulatory strategies [5]. The gap between the real and the desired by means of cognitive anticipation thus motivates its reduction. This requires proactive control and feedback control. The role of goals in behavioral change led by selfefficacy is crucial: they are used as tools for measuring the individual's potential, the actual situation, the adjustments, for motivate for setting the requirements for self evaluation.

\section{B. Goals setting}

The key objective of the goal-oriented approach is to facilitate patients' engagement in activities that are meaningful and significant to them [6,7]. The interaction between the environment and the goal is the main principle underpinning the goal-oriented approach, which is derived from the dynamic systems of motor control theory and occupation-based therapy models [8]. Unlike conventional interventions that focus on improving physical impairment and correcting function, the goal-oriented approach responds to ecological models and its variables of person, environment and occupation and the interaction between these [9]. Goal setting has a specific role and meaning during rehabilitation. The approach of occupational therapy (ibid.) advocates providing the patient with goal-based skills. The goals should be specific, measurable, activity-related, realistic and time-specified, and benefit from positive environmental cues, like the support of therapists or the family. Goals are effective in that they rely on motivation, which is a fundamental source for the patient's improvement, while at the same time being difficult to affect positively by the external. At the same time, emotions and meaning (making, maintaining, searching) are involved in the motivational processes that can end in the creation of a goal, which can be implemented during a therapeutic path.

\section{Motivational Interviewing}

To trigger behavioral change, professionals adopt various methods. Motivational Interviewing (MI, [10]) is a communication approach that starts by eliciting the values of the individual and comparing them with his actual behavior, with the intention of provoking a motivational reaction that should ultimately lead to behavioral change. The methods for fostering motivation are valuable because it is a difficult element to interact with and affect, being composed of intrinsic properties and protected in the identity of the individual. For example, MI is focused on what the individual feels, trusts and does, and the external role of the professional is limited to a restricted set of possible actions. The following sequence might be adopted: (1) try to understand the person's frame of reference, listening to him with a reflective echo of his feelings and experiences; (2) communicate to the patient your acceptance, affirmation, and empathy; (3) elicit and selectively reinforce the problems he mentions, his concerns, desires and intention to change, making with him an inventory of the resources he has at his disposal in order to produce a behavioral change; (4) monitor his progress towards being ready to apply his behavioral change; and (5) constantly affirm his freedom of choice and the self-directness of his behavior. MI restates the conversational implications of the interaction, in the direction of the patient with a specific focus on trying to trigger the willingness to self manage.

\section{Transtheoretical Model}

The Transtheoretical Model (TTM, [11]) is a predictive tool for modeling behavioral change, which is often an integrative strategy for managing chronic illnesses. According to this model, people pass through different stages when modifying their habits. Sequential processes of change stand between the states and sets of activities, in which individuals alter their experiences and/or environment, in order to modify their feelings, behaviors, beliefs, cognitions, or relationships. There can be several variables implied, such as social pressure and the modulation of self-efficacy. The TTM takes the individual through five stages, starting from awareness, preparation, taking action, and then maintaining the desired behavior. The change process follows a general curvilinear shape, with a peak in the course of action and descending in the last part. Diverse cognitive activities, perspectives, and reflections characterize all the different phases (ibid. p. 211).

\section{E. Scientific reasoning and decision making}

This model of self-management tends to refer to chronic illnesses that need to be managed by means of reducing their symptoms. Scientific reasoning and decision-making [12] are also effective for the individual's perception of his own symptoms as a method to support behavioral change or activity pacing/self care. It is a set of skills aimed to find the right treatment strategies when symptoms come up. Its main tenets are: considering each symptom as separate, generating a number of testable treatment alternatives, using a personal database for selecting the most efficacious treatment strategy, adjusting the stepwise treatment to fit changes in the severity of the symptoms, eschewing preconceived notions about symptoms management, thinking more in terms of probability regarding the potential outcomes, and avoiding an overreliance on memory regarding the illness and its treatment. This allows the patient to evaluate and make judgments about his symptoms, and to check any changes that occur in terms of the antecedent conditions that may have led to the modifications, the choices they might make in order to alter their condition and the potential consequences of their actions.

\section{F. Acceptance and Commitment Therapy}

Acceptance and Commitment Therapy (ACT) is a cognitive behavioral therapy (CBT) [13] that represents a way to manage the chronic manifestation of symptoms, like in chronic pain. It can be summarized from Hayes et al. [14] as follows. Humans live in an intensely verbal world. Verbal 
behavior tends to overwhelm all other forms of activity. Language has mostly evolved as a form of social control and danger signaling, and thus over used. Making use of language to deal with our emotions means, as a consequence, that we think verbally about a verbally shaped inner entity, and our emotions are experienced under the rules of verbal reasoning. This could lead, as a consequence, to emotional suppression: the attempt to become averse towards certain feelings and avoid them, thus denying, in effect, a part of ourselves. Refusing negative thoughts and feelings can be dysfunctional: the model of health 'out with the bad, in with the good" rejects the mechanism of pain as a part of human physiology. Also, when we rivet attentive processes onto negative thoughts or feelings with the intent of eliminating them, we usually increase their frequency, intensity, and duration. ACT starts from the tenet that bad feelings form part of our history, being brought into the present by the current context. The first phase of ACT is Acceptance, rather than avoidance. The second phase is Choice and Committed Action, starting from the tenets that overt behavior is changeable. The last phase is Taking Action. Thus, the ACT model incorporates both acceptance and change.

\section{G. Activity pacing}

Activity Pacing, or AP $[15,16]$ is closely related to ACT, as a practice supporting the latter's cognitive approach to a condition; for example, those suffering chronic pain can benefit from these two interrelated approaches, and can also be guided by goal setting and pursuit. The prerequisite of this practice is to be able to cope positively with unpredictable pain. Individuals who are suffering from pain tend to have a wave-like pattern of activity, which reproduces itself. AP involves the attempts to maintain a constant level of activity, avoiding overdoing things in the absence of pain and trying to remain active when the symptoms emerge. In this way, the individual has a stable pattern of activity through containing the consequences of his manifestations of pain; this also improves his quality of life and raises the levels of selfefficacy.

\section{H. Social support}

Beside the fundamental role of carers in self-management and rehabilitation [17], organized thematic groups, involving individual, face-to-face contact, are useful for triggering and maintaining motivation in people to continue their selfmanagement practices [18]. This is well known in the field of occupational therapy. What is less known is the amount of progress that an individual can make when exposed to a social network. Group meetings once a week, clubs, and mailing lists are beneficial from both the practical and emotional perspectives. They help patients to solve their problems and raise their mood, leading them to adopt a far more positive attitude towards their self-care and self-management. This is why a self-management toolkit could be completed by a social network system that matches up different patients for communication purposes. There are various forms of social support that can be provided and shared: practical support (instrumental, aid, tangible), informational support (advice, guidance) and emotional support (esteem, belonging, moral support) (ibid.). The effectiveness of social support also gives credence to an ecological perspective of self-management and rehabilitation, while taking into consideration the patient, who is immersed in a system created by himself, the professionals and his environment as a whole.

\section{ICT PROJECTS FOR BEHAVIOR CHANGE}

What follows is an analysis of some representative projects that have adopted some of the described tools for supporting self-care and self-management. They combine interactive tools, ambient displays, mobile, sensing technologies and social networks in order to promote behavioral change and support distance monitoring. Most of these attempts rely on theories, like self-efficacy, goal setting, or TTM. The effectiveness of these technologies is represented with the in corporation of these theories in their form factors and interaction frameworks [20]. Devices allowing, by means of meaningful feedback, the self-measuring of self-efficacy parameters goal setting are available in the shape of animated visualization tools supporting behavior change. The transtheoretical model is realized while tracking behaviors, thus facilitating awareness, action and maintenance. CareNet Display [21] is focused on distance caring for the elderly but, by providing feedback on areas like meals, medication, outings, activities, mood, and falls, it also gives supports for behavioral change. It is mainly a digital frame, with icons about the named topics, that are used as evidence of undesirable behavior (like falling or a failure to take medication); it can be accessed remotely by a distance carer and so present an overview of the patient's data. Other possible data that could be accessed remotely by distance carers could include (ibid. p. 5): disease-specific measurements, vital parameters, mood, a calendar, household needs, visits, weight, water intake, messages, bathing, car trips, distance walked, dressing, phone calls. CareNet adopts computation and visualization for providing meaningful feedback and also information for the carer, it tunnels the interaction and being located in the home setting as like a frame, makes use of the kairos factor [19]. A frame format is also adopted for Flowie [22], a digital coach that aims to persuade the users to walk more providing meaningful feedback. The technology of Flowie adopts goal setting and self-monitoring as motivational tools. The final result is an ambient display that gives feedback on daily and weekly activity with different visualizations: an animated flower, the number of steps taken compared with the target, and the amount of daily/weekly activity. The concept of the flower was inspired by the UbiFit garden [23], in which a mobile phone display shows, in the form of a flower, the various target activities of the individual (walking, running, cycling, etc.). The UbiFit glanceable display has a stylized representation of the physical activities undertaken and the goals achieved in order to keep the individual focused on the 
act of self-monitoring while at the same time fostering motivation. The kairos factor is represented by the use of the mobile phone as vehicle for feedback. Meaningful visualization as avatars is also used in the Fish'n Steps project [24]. The characters employed also support competition/social networking/peer pressure. Fishes in a tank represent a group of people's walking activity. According to the participants' activity, they can be larger or smaller, or have a healthy or sick appearance. The overall group values were reflected by the appearance of the fish tank. Public displays showing different fish tanks of the participants were available. According to the TTM, which inspire the project, information about their health needs allowed to change the users' habits. Also, the mechanisms of teamwork and competition were developed due to grouping different people together in the same visualized tank. Another project in which social relationships strongly supports monitored activity is Chick Clique [25], that is intended to motivate teenage girls to walk more. Feedback on their number of steps appears on their palmtop and is shared with the group of participants who can motivate with each other via SMS. Information about individual goals and group performance are also fed back via SMS. In this project the kairos factor is represented by both the use of mobile phone display and of the SMS for making peer pressure.

\section{CONCLUSION}

The described projects successfully demonstrate how effective cognitive models can be applied in design settings to provide supportive tools for self-management, self-care and behavioral change. The range of design problems can be addressed to possible solutions that embody theories (e.g. self efficacy, MI, TTM), design options (e.g. kairos, social networking, tunneling, presence) and user needs (e.g. mobility, the home setting, belonging), in order to provide effective tools for supporting chronically ill patients.

\section{ACKNOWLEDGMENT}

This paper is an output of the participatory design experience between Health and Social Care researchers and HCI specialists in the context of the project SMARt2 (www.thesmartconsortium.org), which is supported by EPSRC EQUAL5 initiative (No. EP/F002815/1).

\section{REFERENCES}

[1] Barlow, J., Wright, C., Sheasby, J., Turner, A., Hainsworth, J., "Selfmanagement approaches for people with chronic conditions: a review". Patient Education and Counselling, 2002, Vol. 48: 177-187.

[2] Lorig, K.R., Holman, H.R.,"Self-Management Education: History, Definition, Outcomes, and Mechanisms". Ann behav Med 2003; 26(1): 1-7.

[3] Bandura. "Human agency in social cognitive theory". American Psychologist. 1989, Vol.44, No.9, 1175-1184.

[4] Pajares, F. "Overview of social cognitive theory and self-efficacy". 2002. Retrieved Aug, 18, 2009, from http://www.emory.edu/EDUCATION/mfp/eff.html
[5] Bandura, A. Self-efficacy. The Exercise of Control. New York: W.H. Freeman and Company, 1997.

[6] Siegert, R.J., Taylor, W.J., Theoretical aspects of goal-setting and motivation in rehabilitation. Disability and Rehabilitation, 2004; vol. 26, No.1, 1-8.

[7] Mastos, M., Miller, K., Eliasson, A.C., Imms, C., "Goal-directed training: linking theories of treatment to clinical practice for improved functional activities in daily life". Cinical Rehabilitation 2007; 21: 4755 .

[8] Lesensky, S., Kaplan, L. "Occupational therapy and motor learning: putting theory into practice". Occupational Therapy Practice, 2000, Vol. 5: 13-16.

[9] Kielhofner, G. A Model of Human Occupation: Theory and Application, Philadelphia, PA, Williams and Wilkins, 2002.

[10] Rollnick, S., Miller, W.R., Butler, C.C. Motivational Interviewing in Health Care. Helping Patients Change Behavior. New York, The Guilford Press, 2008.

[11] Grimley, D., Prochaska, J.O., Velicer, W.F., Blais, L.M., DiClemente, C.C. , "The Transtheoretical Model of Change". In Brinthaupt, T.M., Lopka, R.P. (Eds.) Changing the Self. Philosophies, Techniques, and Expriences. Albany (NY): State University of New York Press, 1994.

[12] Creer, T.L. "Strategies for Judgment and Decision-Making in the Management of Childhood Asthma". Pediatric Asthma, Allergy \& Immunology. Vol.4, No.4, 1990.

[13] Taylor, R.R., Cognitive Behavioral Therapy for Chronic Illness and Disability. New York, Springer, 2006.

[14] Hayes, S., Strosahi, K.D., Wilson, K.D., Acceptance and Commitment Therapy: An Experiential Approach to Behavior Change. New York: The Guilford Press, 1999.

[15] Vowles, K.E., Sorrell, J.T. "Life with Chronic Pain: An Acceptancebased Approach. Therapist Guide and Patient Workbook", 2007 (Manuscript).

[16] Vowles, K.E., Wetherell, J.L., Sorrel, J.T., "Targeting acceptance, mindfulness, and values-based action in chronic pain: findings of two preliminary trials of an outpatient group-based intervention". Cognitive and Behavioural Practice, Vol. 16, Issue 1, Feb 2009, pp. 49-58.

[17] Parker, G, Lawton, D. Different Types of Care, Different Types of Carer: Evidence from the General Household Survey. London: HMSO, 1994

[18] Isaksson, G., Lexell, J., Skär, L., "Social Support Provides Motivation and Ability to Participate in Occupation". OTJR: Occupation Participation and Health. Winter 2007, Volume 27, Number 1. 23 - 30.

[19] Fogg, B.J. Persuasive Technology. Using Computers to Change What We Think and Do. San Francisco (CA): Morgan, Kaufmann Publishers, 2003

[20] Cooper, A., About Face 3. The Essentials of Interaction Design Indianapolis, IS: Wiley Publishing, 2007.

[21] Consolvo, S., Roessler, P., Shelton, B.E., The CareNet Display: Lessons Learned from an In Home Evaluation of an Ambient Display. Proceedings of UbiComp 2004. Nottingham, UK, September 7-10, 2004.

[22] Albaina, M, I., Visser, T., van der Mast, C.A.P.G., Vastenburg, M.H., "Flowie: A Persuasive Virtual Coach to Motivate Elderly Individuals to Walk". 3rd International Conference on Pervasive Computing technologies for Healthcare, April 1-3, 2009, London, UK.

[23] Consolvo, S., Klasnja, P., McDonald, D.W., Avrahami, D., Froehlich, J., LeGrand, L., Libby, R., Mosher, K., Landay, J.A., "Flowers or Robot Army? Encouraging Awareness \& Activity with Personal, Mobile Displays". UbiComp'08, September, 21-24, 2008, Seoul, Korea.

[24] Lin, J.J., Mamykina, L., Lindtner, S., Delajoux, Strub, H.B. , "Fish'n'Steps: Encouraging Physical Activity with an Interactive Computer Game". Proceedings of UbiComp 2006, September 17-21, Orange County, CA, USA.

[25] Toscos, T., Faber, A., An, S., Praful Gandhi, M., "Chick Clique: Persuasive Technology to Motivate Teenage Girls to Exercise". CHI 2006, April 22-27, 2006, Montréal, Québec, Canada. 